\title{
THE RELATION OF ENTRANCE LEVEL TO RATE OF PROGRESS IN AURAL COMPREHENSION
}

\author{
ROBERT LADO \\ University of Michigan
}

If we were to measure the effect of a factor in language learning on the basis of final achievement alone our findings would be questioned on the ground that some students might have been more advanced than others to begin with and that as a result the final scores might simply reflect the differences existing before the experiment. Thorndike was aware of this fact when he stated

Individuals from twenty to forty are more nearly on an equality of preparation for Esperanto than they would be for any natural language or branch of mathematics or science. They are, of course, not equal. Variations in knowledge of language and of particular languages are great and make learning much easier for some than for others. Also, some individuals start their learning at a point in advance of the others. ${ }^{1}$

His statement is born out by the tables in the appendix of his book which show a range from 9 to 80 out of a possible 100 on one of the tests of Esperanto administered before the experiments. Esperanto was chosen for his experiments partly because it was thought that initial differences would be smaller in it than in the natural languages, and yet we find that great range of initial scores. Failure to take into account these initial differences, however, seems to be the rule rather than the exception in research on language learning prognosis,

\footnotetext{
' E. L. Thorndike, et al, Adult Learning (New York: The Macmillan Company, 1928), pp. 44-45.
} 


\section{ROBERT LADO}

where final achievement or final semester grades are repeatedly used as the only measure of achievement. ${ }^{2}$

The obvious alternative to the exclusive use of final measures of achievement is the measurement of achievement before and after an experiment. Thorndike followed this plan and used progress as the measure of success. "Progress was measured by the difference in score between a series of four tests given before any study and after the twenty hours" (of study and teaching.) ${ }^{3}$ It will be shown in this paper that the entrance level of the students is related to their rate of progress and that the entrance level must be equalized or its effect in some way eliminated from the data if the findings are to be valid. The paper will also present a practical method for canceling the effect of entrance level, and some implications for research.

II

The isolation of the effect of entrance level arose out of practical considerations. All students are given equivalent tests of aural comprehension at the beginning and at the end of their eight week intensive course in English in the English Language Institute." A large enough number of students not to be dismissed as isolated cases made increases from entrance to final which conflicted with the quality of work, interest, and ability of the students as shown in class. In going

\footnotetext{
'See for example: V. A. C. Henmon, et al, Prognosis Tests in the Modern Forelgn Languages; Publications of the American and Canadian Committees on Modern Ianguages (New York: The Macmillan Company, 1929). R. M. W. Travers, "Significant Research on the Prediction of Academic Success," The Measurement of Student Adjustment and Achievement (Ann Arbor: University of Michigan Press, 1949), pp. 147-190.

Op. cit., p. 45.

The disparity between the objective data supplied by the tests on the one hand and the teachers' estimate of the quality of the work and ability of the students on the other could not be explained on the basis of unreliability of the test since the Test of Aural Comprehension has a reliability coefficient of $.88 \pm .02$. R. Lado, Measurement in English as a Forelgn Language (Ann Arbor: Horace H. Rackham School of Graduate Studies, doctoral dissertation, 1950), p. 46.
} 
over the increases it was observed that large increases tended to occur more frequently among cases with low entrance scores than among cases with high entrance scores. Was the rate of progress, then, related to the entrance level of the students?

In order to verify or reject this possibility 415 cases were tabulated and plotted on the basis of entrance scores and raw improvement. The results obtained are presented in Table I and Figure I.

Table I and Figure I show - after some erratic variation below entrance level 20 due possibly to the small number of cases involved at those levels - a steady decline in raw improvements as the entrance level increases from 20 up. Entrance level is then negatively related to rate of progress in aural comprehension as measured by the test. The same tendency was observed in a tabulation of 418 raw increases in structure as measured by another test ${ }^{5}$ and in 50 raw increases in aural perception of the sounds of English. ${ }^{6}$ Those tables were not included in the paper for the sake of clearness and brevity.

\section{III}

That the factor of entrance level is not merely a numerical expression of low ceiling on the test, ${ }_{2}$ or in other words, that students making small raw improvements might have done so because they had reached the top possible score on the test does not seem to be a plausible explanation. All cases in the aural comprehension data had further room for improvement beyond their final scores. Furthermore, a normal decrease of cases at the upper level gives added assurance that the ceiling of the test was adequate.

What we seem to have is a negatively accelerated curve of learning - a not uncommon phenomenon. In the few cases that have been followed beyond the eight week standard period of training a decline in the rate of progress seems to be the

Examination in Structure, Reliability .97, Ibid., p. 68.

- Test of Aural Perception, Reliability .90, Ibid., p. 61. 


\section{ROBERT LADO}

\section{Table I}

\section{AVERAGE IMPROVEMENTS AT VARYING ENTRANCE LEVELS}

Aural Comprehension

\begin{tabular}{c}
$\begin{array}{c}\text { Entrance Score } \\
\text { Intervals }\end{array}$ \\
\hline $0-9$ \\
$10-19$ \\
$20-29$ \\
$30-39$ \\
$40-49$ \\
$50-59$ \\
$60-69$ \\
$70-79$ \\
$80-89$ \\
$90-100$
\end{tabular}

\begin{tabular}{c} 
Number of \\
Cases \\
\hline
\end{tabular}

Mean Raw Improvement

35

26

28

26

23

19

14

10

6

0

rule. We may thus assume that the s!ower rate of progress shown at high entrance levels indicates that the period of rapid progress had already taken place when the entrance test was administered.

Actually, we need not be too skeptical of the statistical evidence of a negative relation between entrance level and rate of progress since such evidence is in accord with our knowledge of quantitative linguistic analysis and with psychological thinking. We know for example that the patterns that signal linguistic meaning are sometimes quite general and sometimes more limited, e.g. the so-called " $s$ " plural accounts for 95 per cent of all plurals in Modern English, ${ }^{7}$ while the remaining 5 per cent of the occurrences includes a variety of other patterns and individual words. It is easy to see that a student will come in contact with the $-s$ plural very early in his study of English and that once he has learned it he can handle the bulk of English plurals. On the other hand when he

${ }^{7}$ Charles C. Fries, American English Grammar (New York: D. AppletonCentury Co., Inc., 1940), p. 42. 


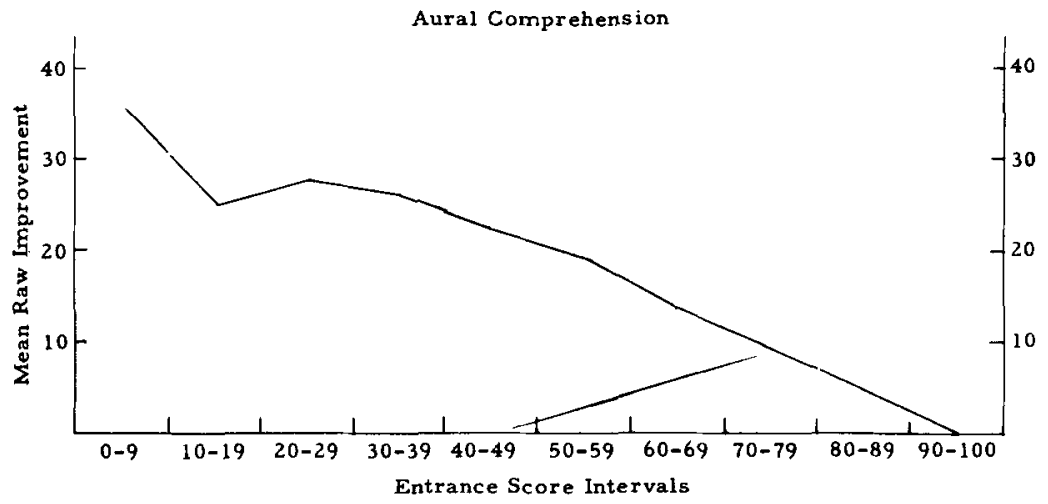

Figure I. Average Improvements At

Varying Entrance Levels

learns the plural men, for example, he has acquired only a very limited part of the English Language even though the effort required in learning it may have been somewhat comparable to that required in learning the $-s$ plural. It should not be surprising to see him make greater progress as he learns the more general patterns and slower progress as he learns the more limited patterns of the language.

From a psychological point of view we note that the learner will acquire more rapidly those elements of the foreign language that operate on habits already established for the native language, less rapidly those elements that require the acquisition of new habits, and least rapidly those in which the new habits conflict with the linguistic habits already established by the native language. What remains to be learned by students with high entrance scores will tend to be matters that involve new habits conflicting with their native language habits. Progress in these will usually be slow.

- Something of the effect of such transfer is summarized by J. A. McGoech, The Psychology of Human Learning (New Yo:k, London: Longmans, Green and Co., 1946), pp. 55-58. 
The relation of entrance level to rate of progress is not necessarily a causal one. It is rather a symptom of a variety of factors. We need not accept it as the final statement of the phenomena observed in our data, but until we are able to isolate the causal elements and until we are able to measure them effectively we must not ignore their total impact which has here been called the relation of entrance level to rate of improvement.

\section{IV}

We have in fact defined two likely errors in research on factors of language learning. The first consists in using only final measures of achievement thus failing to take into account differences existing at the beginning of the experiment. Thorndike planned his experiments to overcome this error, but Cheydleur for example was not able to avoid it even though he was somewhat aware of it. ${ }^{8}$ Many studies avoid the issue by calling their criterion "success" in college, rather than achievement; and then they define success as the grades received. ${ }^{10}$ If we define success in foreign language as the relative amount of the language learned by the student, such experiments cannot be fully accepted because they are subject to the first error.

\footnotetext{
-F. D. Cheydleur, "An Experiment in Adult Learning of French at the Madison, Wisconsin Vocational School," Journal of Educational Research, 26 (Dec., 1932), pp. 265-66:

"This testing was done at the end of the respective courses. No language aptitude tests were given at the beginning of the elementary courses nor were equivalent forms of the standardized language tests administered before the finals to bring out the relative amount of language knowledge gained between two fixed periods by the vocational group and the university group. As desirable and valuable as this information might be, it seemed advisable to do without it rather than lose the adult students who, in spite of their real interest in the subject and their fine spirit dreaded being examined more than did the younger university group."

${ }^{10}$ This point of view also represents a difference in philosophy. Their purpose is to find those who may not pass in language courses and weed them out before they go through the frustration of failing the course. My goal in trytag to discover factors is to improve the teaching and the materials so that more students will learn more of the foreign language.
} 
The second error consists in using raw increases without correction for entrance level thus ascribing to other factors those differences that seem to appear normally at different levels. Thorndike's experiments, mentioned above, may now be open to question on this ground.

In looking at the initial scores in Thorndike's experiments it is obvious how difficult it would have been with the limited number of cases available to have been able to pair students on the basis of initial scores. If one wishes to make comparisons from year to year, from one institution to another, the samples will often be reduced to insignificance.

Correlations - which lend themselves well to the isolation of special abilities affecting language learning - will be distorted if in the sample the ability being investigated is not evenly distributed over the range of entrance levels. These practical considerations led to the development of a statistical procedure to eliminate the effect of entrance level as completely as possible.

\section{V}

An elementary unit which largely eliminates the changes in rate of progress connected with initial level is one which we may call the mean improvement unit. The mean improvement unit is the average improvement at any given level. The mean improvement in aural comprehension at entrance level 63-67 for example is 14 points; therefore by definition the mean improvement unit at that level is 14 . If a student at that level makes a raw improvement of say 28 points, his improvement in mean improvement units is $28 / 14$ or $2: 00$; if his raw progress is 21 points his converted progress is $21 / 14$ or 1.50 ; $14 / 14$ would be $1.00 ; 7 / 14$ would be $.50 ; 0 / 14$ would be 0 ; etc. By this device all raw improvements that equal the average improvement at their particular level will become 1.00 , all raw improvements that are twice the size of the mean improvement at their particular level will become 2.00 and all raw improvements that are one-half the average at their particular level will become .50, and so forth. Since the average improvement at any level contains the "effect" of entrance 


\section{ROBERT LADO}

level - it was through the average improvements that we verified the differences in rate of progress related to entrance level - we actually equalize these differences with a minimum of distortion of the data. Other units such as standard scores and percentile scores were found less satisfactory.

Once a mean improvement unit has been established under known conditions it is possible to carry on experimentation with relatively small numbers of cases by reducing all improvements to mean improvement units. Such a unit was developed and a table for easy conversion was made on the basis of progress in our eight week intensive course. ${ }^{11}$ The mean improvement unit used in this way amounts to a new method for standarizing achievement tests.

Another method that might be effective in equalizing these differences in rate of progress accompanying differences in entrance level is that of partial correlation. Samples will always have to be larger, however, with this method.

VI

In conclusion, then, we may say that research involving achievement in language learning should be based on differences between initial and final measures - i.e. rate of progress - , and that differences in rate of progress accompanying differences in initial level should be equalized or eliminated.

${ }^{11}$ R. Lado, op. cit., pp. 117-18. 